\title{
Optimum combination of machining parameters during drilling of aluminium 7075 alloys using Grey based Taguchi approach
}

Reddy SREENIVASULU, Chalamalasetti Srinivasa RAO

DOI: 10.30464/jmee.2020.4.3.227

Cite this article as:

Sreenivasulu R., Rao Ch. S. Optimum combination of machining parameters during drilling of aluminium 7075 alloys using Grey based Taguchi approach. Journal of Mechanical and Energy Engineering, Vol. 4(44), No. 3, 2020, pp. 227-238.

\section{VOLUME 4(44) | No. 3 | SEPTEMBER 2020} ISSN 2544-0780 | e-ISSN 2544-1671

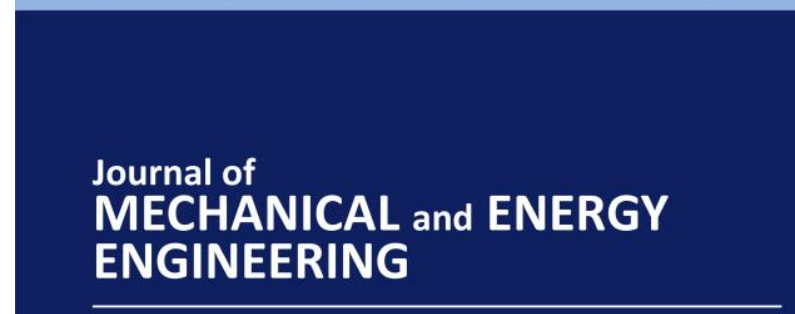

Editor-in-Chief

Waldemar Kuczyński

Editors

Wojciech Kapłonek | Krzysztof Nadolny
Journal of Mechanical and Energy Engineering

Website: jmee.tu.koszalin.pl

ISSN (Print): 2544-0780

ISSN (Online): 2544-1671

Volume: 4(44)

Number: 3

Year: 2020

Pages: 227-238

Article Info:

Received 29 August 2020

Accepted 15 September 2020

\section{Open Access}

This article is distributed under the terms of the Creative Commons Attribution 4.0 (CC BY 4.0) International License (http://creativecommons.org/licenses/by/4.0/), which permits unrestricted use, distribution, and reproduction in any medium, provided you give appropriate credit to the original author(s) and the source, provide a link to the Creative Commons license, and indicate if changes were made. 


\title{
OPTIMUM COMBINATION OF MACHINING PARAMETERS DURING DRILLING OF ALUMINIUM 7075 ALLOYS USING GREY BASED TAGUCHI APPROACH
}

\author{
Reddy SREENIVASULU ${ }^{1 *}$, Chalamalasetti Srinivasa RAO ${ }^{2}$ \\ 1* R.V.R \& J.C.College of Engineering (Autonomous), Department of Mechanical Engineering, Guntur, \\ Andhra Pradesh, Email Address: rslu1431@gmail.com, https://orcid.org/0000-0002-7442-7141 \\ ${ }^{2}$ University College of Engineering (Autonomous), Department of Mechanical Engineering, Andhra \\ University, Visakhapatnam, Andhra Pradesh, INDIA
}

(Received 29 August 2020, Accepted 15 September 2020)

\begin{abstract}
From ancient days to till today manufacturing industries, especially making of holes on the parts during drilling process for precision assembling of parts facing problems with burr formation. Drilling operation is one of the finishing operation in the production cycle, removing of burrs during drilling process is a time consuming and non-value added process to the manufacturing sector. So reducing the size of burrs is the main aim of the present study. In the present work, optimization of burr size is considered during drilling of aluminium 7075 alloy. In this connection, experiments are conducted based on Grey based Taguchi. From Grey relational grades of responses selected optimal combination of parameters to attain multiple performance characteristics of responses with a corresponding higher grey relational grade. For identifying the most significant input parameters that influence the output responses ANOVA is conducted. Based on interaction effect plots of data means of responses from results of ANOVA, confirmation tests are conducted by choosing most significant parameters. Finally, observations reveals that feed rate, point and clearance angles are the most influential factors on burr size and also experimental results divulge that the lower the thrust force causes to decrease the burr height. The proposed approach is helpful to the budding entrepreneurs in the related areas to select optimal combination of drilling parameters to attain multiple performance characteristics of responses especially in burr size to prevent the post finishing operations up to certain extent.
\end{abstract}

Keywords: drilling, burr size, surface roughness, roundness error, thrust force, torque, Taguchi method, grey relational analysis

\section{INTRODUCTION}

The burr, which is a plastically deformed material, engendered during drilling is a preventable output and often lowers the surface quality, diminishes the product life and acceptability of the product. Total elimination of burrs during drilling process is a trivial task, however with proper selection of process parameters, it can be curtailed. Selection of process parameters according to workpiece material and hole quality requirement is critical for the minimization or prevention of burr formation. However, simulation models developed so far for the interaction between process conditions; material properties and burr formation are limited. Therefore, the burr, an unintended outcome of machining processes, has been a widely recognized problem in the industry. Burrs ruins the integrity of design of the part. All these side effects causes unnecessary cost to the industry in various forms such as additional machining, compensation, service, redesign and collateral damage on the company reputation. Therefore, in most cases, it is a must either to remove or to secure the burr in order to prevent from being detached as of the part. 
Traditionally, burr problems had been considered unavoidable so that most efforts made on removal of the burr as a post process. Nowadays, a trend of manufacturing is an integration of the whole production flow from design to end product. Manufacturing problem issues are handled in various stages, even from design stage. The methods of describing the burr are gaining much attention in recent years for the systematic approach to resolve the burr problem at various manufacturing stages. The proposed work flow diagram is shown in Fig.1.

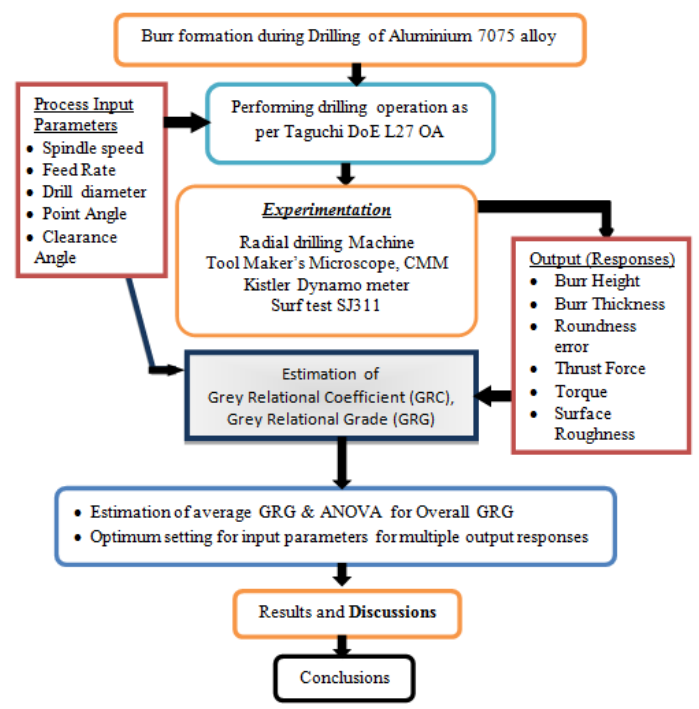

Fig. 1. Flow chart for proposed work

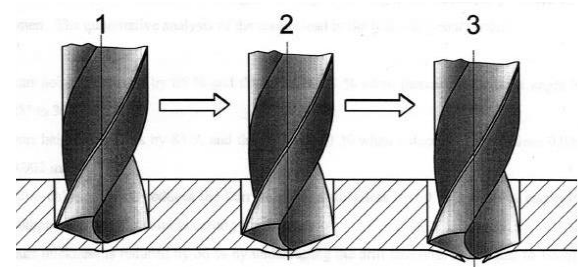

Fig. 2. Exit burr formation in three different stages [1]

While drilling, two burrs are formed: a small entrance burr and a much bigger exit burr. The process of drilling exit burr formation can be divided into three different stages as shown in Fig. [1], these are (1) When the drill approaches the exit side of the workpiece, the chisel edge of the drill produces the plastic deformation of the work beneath material (2)Then a bulge develops on the bottom surface of the workpiece. The remaining material in front of the corners of the tool is still strong enough to withstand the thrust force of the drilling operation. Thus, no plastic deformation occurs in this region and the normal cutting process continues (3) As the material beneath the chisel edge reaches its maximum elongation, it starts to tear and finally the drill breaks through and the remaining material is bent out and becomes the burr.

Kim et al [5] categorized by CODEF (Consortium on Deburring and Edge Finishing), drilling burrs as uniform burr with or without a drill cap, crown burr or petal burr according to their shapes and formation mechanism. Two types of burrs, uniform burr (type I: small uniform burr, type II: large uniform burr) and crown burr, for stainless steel and three types of burrs, uniform burr (type I: small uniform burr, type II: large uniform burr), transient burr, and crown burr, for low alloyed steel were found [Fig.3].

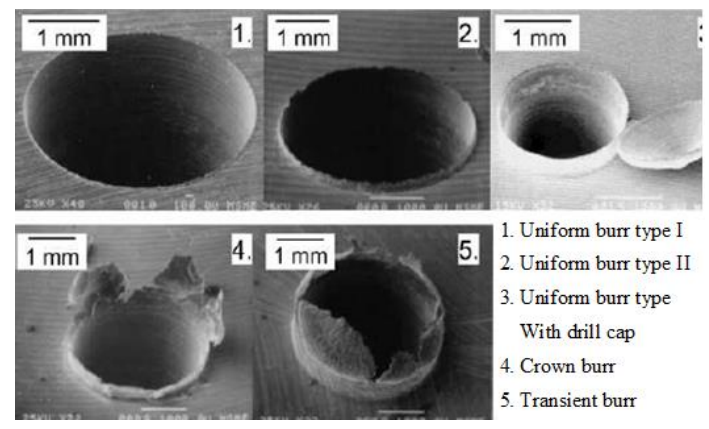

Fig. 3. Typical drilling burr types according to CODEF [2]

\section{PARAMETER SELECTION}

Many researchers contributed for the development of drilling process and proper selection of process parameters in ascertaining good quality of the products. However the geometry of the twist drill and consequently its specifications are very complex. According to Galloway [5], drill specification consists of twenty elements such as the flute, body clearance and the chisel edge, thirteen measurements, such as the diameter and web-thickness, and eight angles. All these add up to forty-one definitions [6] given by the B.S 328 - 1959. Galloway's specification and those of the B.S. $328-1958$ are nevertheless very similar. Both the B.S. 328 -1959 and Galloway do not specify the appropriate or acceptable values for web-thickness, helix angle (or the pitch length), chisel edge angle and other such angles. One of the reasons for not specifying these parameters is that they should vary according to the material being drilled, depth of the holes and the hole accuracy required. Thus, parameters selection is left to the users to specify and the manufacturer to recommend these parameters in each particular application. Another difficulty in specifying the drill geometry is that all angles and elements are inter-related, sometimes not practicable. With the introduction of high speed steel, consequent design improvement and lower manufacturing costs, twist drill bits become indispensable tools in industry. So in the present work, HSS (High Speed Steel) twist drill bits are used for experimental work due to more 
economical and commonly adopted in all medium scale manufacturing industries.

\subsection{Selection of material for experimentation}

According to transparency market research analysis survey conducted in year 2014 among demand of aluminium alloys, which is low cost, abundantly available light weight material demand in industry to make components in different trades in the world wide market. The demand for these alloys (Fig. 4) is classified into Northern states in U.S.A, European region, Asia pacific zone, and rest of the countries. The share of more than $60 \%$ of aluminium alloys in the world trade in 2013 is occupied by Asia pacific market, mainly driven by the need in the development of infrastructural projects and the transportation industry in China and India being the largest consumers of aluminum alloys. Asia pacific market is anticipated to become the most rapidly developing regional segment by 2020 .

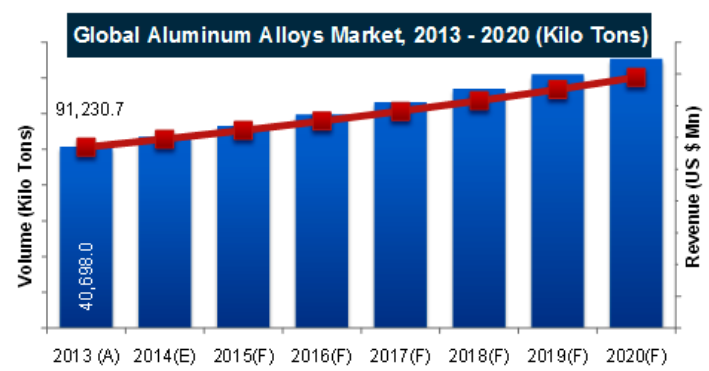

Fig. 4. Global aluminium alloys market 2013-2020 [7]

Especially in aircraft, automotive industries [7] for structural and making components with reduction of weight purposes aluminium alloys are required and needs making numerous number of holes in drilling to assemble the components. So, due to day to day increase in demand of aluminium alloys in the areas of aircraft, automotive and marine industries aluminium 7075 alloy was chosen to conduct drilling experiments in the present work.

\subsection{Selection of input parameters}

The requirement of the present manufacturing sector especially aerospace and automotive sectors from the researchers is to develop the controlling methods to prevent or minimize the burrs during drilling, because it is critical problem faced by the industry. So, in order to minimize the burrs during drilling, understand the various input process parameters that influence the burr formation. Sofronas, discussed about influencing process parameters on burr formation in drilling in 1975 , followed by many researchers' [8-11] who have attempted similar studies and summarized several factors governing burr formation in drilling. In the present study, variable drill point geometry, spindle speed and feed rate are considered to perform the drilling experiments as per
Taguchi's design plan. In the present work, the alteration of clearance and point angles carried out under the presence of a skilled operator on Tool \& Cutter grinding machine to attain desired dimensions.

\section{EXPERIMENTAL SETUP}

Experimentation was performed on radial drilling machine to perceive the burr formation and its parameters. The Kistler dynamometer is fitted on the work table of the radial drilling machine to read the forces generated during the experimentation. The burr size (height and thickness) of the drilled holes, after completion of experimentation, output parameters are measured using tool maker's microscope. After edge finishing of each hole, roundness error is measured equidistantly along the periphery of the holes using the coordinate measuring machine. The surface roughness of the drilled holes is measured using a surface roughness tester Mitutoyo surf test SJ301. In the present work, a radial drilling machine to perform different size of holes on Al 7075 alloy work pieces chosen to conduct experimentation. The composition of Al 7075 alloy shown in the Table 1.

Tab. 1. Composition of Al 7075 alloy

\begin{tabular}{cc}
\hline Element & $\mathrm{Wt} \%$ \\
\hline $\mathrm{Si}$ & 0.32 \\
\hline $\mathrm{Cu}$ & 1.4 \\
\hline $\mathrm{Zn}$ & 5.8 \\
\hline $\mathrm{Iron}$ & 0.3 \\
\hline $\mathrm{Mn}$ & 0.28 \\
\hline $\mathrm{Mg}$ & 2.7 \\
\hline $\mathrm{Ti}$ & 0.2 \\
\hline $\mathrm{Cr}$ & 0.24 \\
\hline $\mathrm{Al}$ & Remaining
\end{tabular}

The tools used for drilling operation are HSS-R (DIN 338) twist drills and commercially available with diameters of 8,10 and $12 \mathrm{~mm}$ with $118^{\circ}$ point angle and $30^{\circ}$ constant helix angle.

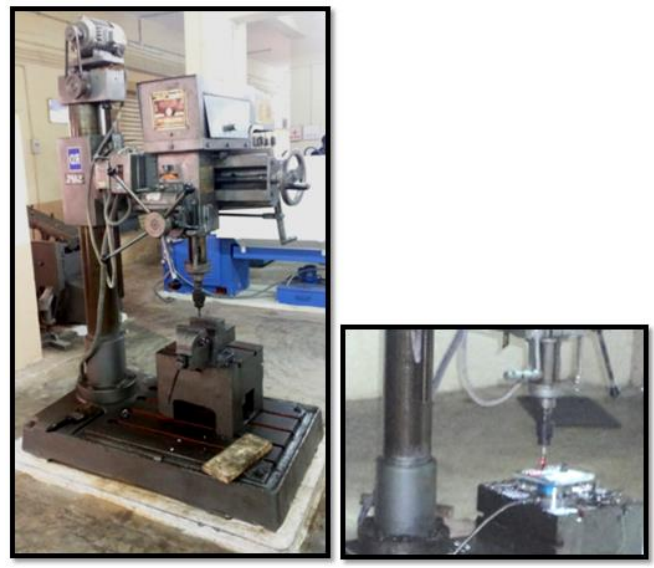

Fig. 5. Radial drilling machine \& Dynamometer setup 
A Kistler type 9272, four components dynamometer was used to measure thrust force and torque and the signal was processed to the computer by a type 5070 multichannel charge amplifier, data acquisition card and graphical images displaying mathematical processing of thrust force ad torque signals recorded with Dynoware software 2825A.The technical specifications of the machine used to measure drilling forces is depicted in Table. 2

Tab. 2. Technical specifications of dynamometer

\begin{tabular}{ll}
\hline Model & Type 9272 \\
\hline Make & $\begin{array}{l}\text { Kistler Instrumente AG, CH8408, } \\
\text { Winterthur, Switzerland }\end{array}$ \\
\hline Components & $\begin{array}{l}\text { Four components }\left(\mathrm{F}_{\mathrm{X}}, \mathrm{F}_{\mathrm{Y}}, \mathrm{F}_{\mathrm{Z}} \text { and }\right. \\
\left.\mathrm{M}_{\mathrm{Z}}\right) \text { dynamometer }\end{array}$ \\
\hline Measuring range & $\begin{array}{l}\text { Fx, Fy: }-5 \text { to }+5 \mathrm{kN} ; \mathrm{Fz}-5 \text { to } \\
\text { 20KN, Mz: }-200 \text { to }+200 \mathrm{Nm}\end{array}$ \\
\hline Amplifier & $\begin{array}{l}\text { type } 5070 \text { multichannel charge } \\
\text { amplifier }\end{array}$ \\
\hline Data acquisition card & PC-Card DAS 16/16 Type 2855A5 \\
\hline Software & Dynoware Type 2825A \\
\hline$D \times d \times H$ mm & $100 \times 15 \times 70$ \\
\hline Calibration done & Yes $/$ No \\
\hline
\end{tabular}

\section{EXPERIMENTATION}

In the present experimental investigation, the parameter optimization of drilling with twenty seven

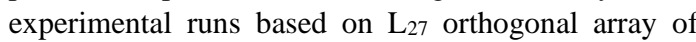
Taguchi method is used to perform holes on work pieces. The input drilling parameters such as spindle speed, feed rate, drill diameter, point angle and clearance angle are optimized with a consideration of multiple performance characteristics (output responses) viz., burr height, burr thickness, thrust force, torque, surface roughness and roundness error are assessed. A grey relational grade obtained from the grey relational analysis is used to solve the multiple performance characteristics in drilling process. Additionally, the analysis of variance (ANOVA) is applied to identify the most significant input parameter. Finally, confirmation tests are performed to make a comparison between the experimental results and developed simulation model.

\subsection{Grey based Taguchi approach}

In Grey based Taguchi method [3-5] combines the algorithm of Taguchi method and grey relational analysis to determine the optimum process parameters for multiple responses includes the following steps.

1. Identify the performance characteristics and cutting parameters to be evaluated.

2. Determine the number of levels for the process parameters.

3. Select the appropriate orthogonal array and assign the cutting parameters to the orthogonal array.
4. Conduct the experiments based on the arrangement of the orthogonal array.

5. Normalize the experimental results of burr height, burr thickness, thrust force, torque, roundness error and surface roughness.

6. Perform the data pre-processing and calculate the grey relational coefficient.

7. Calculate the grey relational grade by averaging the grey relational coefficient.

8. Analyze the experimental results using the grey relational grade and statistical ANOVA.

9. Select the optimal levels of cutting parameters.

10. Verify the optimal cutting parameters through the confirmation experiment.

The output parameters recorded for each of the experiments are the Burr height $\left(R_{l}\right)$, Burr thickness $\left(R_{2}\right)$, Roundness error $\left(R_{3}\right)$, Thrust force $\left(R_{4}\right)$, Torque $\left(R_{5}\right)$ and Surface Roughness $\left(R_{6}\right)$. The selected input parameters and their levels as per Taguchi's design plan are depicted as in Table 2 and measured output values recorded in and shown in Table 3.

Tab. 3. Plan of experiments

\begin{tabular}{cccccc}
\hline $\begin{array}{c}\text { Exp. } \\
\text { No. }\end{array}$ & $\begin{array}{c}\text { Spindle } \\
\text { speed, } \\
\text { rpm }\end{array}$ & $\begin{array}{c}\text { Feed } \\
\text { Rate, } \\
\text { mm/min }\end{array}$ & $\begin{array}{c}\text { Drill } \\
\text { diameter, } \\
\text { mm }\end{array}$ & $\begin{array}{c}\text { point } \\
\text { angle, } \\
\text { degree }\end{array}$ & $\begin{array}{c}\text { clearance } \\
\text { angle, } \\
\text { degree }\end{array}$ \\
\hline 1 & 465 & 18 & 8 & D & E \\
\hline 2 & 465 & 18 & 8 & 100 & 4 \\
\hline 3 & 465 & 18 & 8 & 100 & 6 \\
\hline 4 & 465 & 20 & 10 & 110 & 4 \\
\hline 5 & 465 & 20 & 10 & 110 & 6 \\
\hline 6 & 465 & 20 & 10 & 110 & 8 \\
\hline 7 & 465 & 26 & 12 & 118 & 4 \\
\hline 8 & 465 & 26 & 12 & 118 & 6 \\
\hline 9 & 465 & 26 & 12 & 118 & 8 \\
\hline 10 & 695 & 18 & 10 & 118 & 4 \\
\hline 11 & 695 & 18 & 10 & 118 & 6 \\
\hline 12 & 695 & 18 & 10 & 118 & 8 \\
\hline 13 & 695 & 20 & 12 & 100 & 4 \\
\hline 14 & 695 & 20 & 12 & 100 & 6 \\
\hline 15 & 695 & 20 & 12 & 100 & 8 \\
\hline 16 & 695 & 26 & 8 & 110 & 4 \\
\hline 17 & 695 & 26 & 8 & 110 & 6 \\
\hline 18 & 695 & 26 & 8 & 110 & 8 \\
\hline 19 & 795 & 18 & 12 & 110 & 4 \\
\hline 20 & 795 & 18 & 12 & 110 & 6 \\
\hline 21 & 795 & 18 & 12 & 110 & 8 \\
\hline 22 & 795 & 20 & 8 & 118 & 4 \\
\hline 23 & 795 & 20 & 8 & 118 & 6 \\
\hline 24 & 795 & 20 & 8 & 118 & 8 \\
\hline 25 & 795 & 26 & 10 & 100 & 4 \\
\hline 27 & 795 & 26 & 10 & 100 & 6 \\
\hline & & 26 & 10 & 100 & 8 \\
\hline 19 & & & & \\
\hline 12 & & 8 & 6 \\
\hline
\end{tabular}


Tab. 4. Data obtained for output responses

\begin{tabular}{|c|c|c|c|c|c|c|}
\hline $\begin{array}{l}\text { Exp. } \\
\text { No. } \\
\end{array}$ & R1 & R2 & R3 & $\mathrm{R} 4$ & R5 & R6 \\
\hline 1 & 0.246 & 0.197 & 0.107 & 281.6 & 113.1 & 1.656 \\
\hline 2 & 0.232 & 0.165 & 0.189 & 235.2 & 155.7 & 2.192 \\
\hline 3 & 0.226 & 0.253 & 0.141 & 395.9 & 249.7 & 1.564 \\
\hline 4 & 0.265 & 0.198 & 0.182 & 232.1 & 171.5 & 1.332 \\
\hline 5 & 0.336 & 0.189 & 0.272 & 291.2 & 173.5 & 1.353 \\
\hline 6 & 0.242 & 0.216 & 0.111 & 265.5 & 127.3 & 1.258 \\
\hline 7 & 0.316 & 0.238 & 0.105 & 336.6 & 199.1 & 1.267 \\
\hline 8 & 0.325 & 0.218 & 0.132 & 283.7 & 157.3 & 1.723 \\
\hline 9 & 0.324 & 0.273 & 0.076 & 252.2 & 158.3 & 2.850 \\
\hline 10 & 0.296 & 0.232 & 0.094 & 241.7 & 134.1 & 1.615 \\
\hline 11 & 0.254 & 0.178 & 0.085 & 237.2 & 156.2 & 2.093 \\
\hline 12 & 0.326 & 0.237 & 0.066 & 395.9 & 209.7 & 1.524 \\
\hline 13 & 0.286 & 0.248 & 0.174 & 262.1 & 144.5 & 1.209 \\
\hline 14 & 0.378 & 0.245 & 0.088 & 208.2 & 165.2 & 1.305 \\
\hline 15 & 0.365 & 0.251 & 0.139 & 268.4 & 137.4 & 1.215 \\
\hline 16 & 0.302 & 0.262 & 0.122 & 346.6 & 274.1 & 1.236 \\
\hline 17 & 0.297 & 0.184 & 0.119 & 280.7 & 147.3 & 1.728 \\
\hline 18 & 0.352 & 0.229 & 0.091 & 252.2 & 232.1 & 2.815 \\
\hline 19 & 0.392 & 0.278 & 0.179 & 246.6 & 213.1 & 1.635 \\
\hline 20 & 0.289 & 0.243 & 0.078 & 236.5 & 177.7 & 2.349 \\
\hline 21 & 0.342 & 0.222 & 0.127 & 305.9 & 219.7 & 1.557 \\
\hline 22 & 0.282 & 0.241 & 0.227 & 272.1 & 184.5 & 1.142 \\
\hline 23 & 0.207 & 0.266 & 0.036 & 298.2 & 165.3 & 1.356 \\
\hline 24 & 0.174 & 0.152 & 0.058 & 345.5 & 241.4 & 1.285 \\
\hline 25 & 0.164 & 0.141 & 0.063 & 396.9 & 249.1 & 1.326 \\
\hline 26 & 0.201 & 0.158 & 0.152 & 286.7 & 197.3 & 1.724 \\
\hline 27 & 0.219 & 0.187 & 0.064 & 362.2 & 238.1 & 2.853 \\
\hline
\end{tabular}

\section{GREY RELATIONAL ANALYSIS (GRA)}

The grey relational analysis based on the grey system theory can be used to solve the complicated interrelationships among the multiple responses effectively. In a grey system part of the information is known and some is unknown. GRA is applied in optimization of process parameters in various machining operations with multiple-responses. In the grey relational analysis, the grey relational grade is used to show the relationship among the sequences. If the two sequences are identical, then the value of grey relational grade is equal to 1 . The grey relational grade also indicates the degree of influence that the comparability sequence could be expert over the reference sequence (Experimental runs). Therefore, if a particular comparability sequence is more important than the other comparability sequences to the reference sequence, then the grey relational grade for that comparability sequence and reference sequence will be higher than other grey relational grades.

\subsection{Data pre-processing}

Data pre-processing is normally required since the range and unit in one data sequence may differ from the others. Data preprocessing is also necessary when the sequence scatter range is too large, or when the directions of the target in the sequences are different. Data pre-processing is a means of transferring the original sequence to a comparable sequence [12-16]. If the target value of original sequence is infinite, then it has a characteristic of the "higher is better". The original sequence can be normalized as follows:

$$
x_{i}^{*}(k)=\frac{x_{i}^{0}(k)-\min x_{i}^{0}(k)}{\max x_{i}^{0}(k)-\min x_{i}^{0}(k)},
$$

when the "lower is better" is a characteristic of the original sequence, then the original sequence should be normalized as follows:

$$
x_{i}^{*}(k)=\frac{\left[\max x_{i}^{0}(k)-x_{i}^{0}(k)\right]}{\left[\max x_{i}^{0}(k)-\min x_{i}^{0}(k)\right]},
$$

however, if there is a definite target value (desired value) to be achieved, the original sequence will be normalized in form:

$$
x_{i}^{*}(k)=1-\frac{\left|x_{i}^{0}(k)-x^{0}\right|}{\max x_{i}^{0}(k)-x^{0}} .
$$

The original sequence can be simply normalized by the most basic methodology, i.e. let the values of original sequence be divided by the first value of the sequence:

$$
x_{i}^{*}(k)=\frac{x_{i}^{0}(k)}{x_{i}^{0}(1)},
$$

where: $i=1 \ldots m ; k=1 \ldots n$. ' $m$ ' is the number of experimental data items and ' $n$ ' is the number of parameters, $x_{i}{ }^{O}(k)$ denotes the original sequence, $x_{i}{ }^{*}(k)$ the sequence after the data pre-processing, $\max x_{i}{ }^{O}(k)$ the largest value of $x_{i}{ }^{0}(k), \min x_{i}{ }^{O}(k)$, the smallest value of $x_{i}{ }^{O}(k)$ and $x_{i}{ }^{O}$ is the desired value. For data preprocessing in the grey relational analysis, all the responses are taken as the "lower is better" (LB). Let the results of 27 experiments be the comparability sequences $x_{i}{ }^{0}(k), i=1-27, k=1-6$. All the sequences after data preprocessing using Equation 2, comparability sequence was obtained. The original (reference) sequences of each performance characteristics are transferred to comparable sequences by normalizing the experimental data. According to the Deng [12] larger normalized results corresponding to the better performance and the best normalized result should be equal to one and then the grey relational coefficients are calculated to express the relationship between the ideal and the actual experimental results. 
Tab. 5. Comparability Sequence

\begin{tabular}{ccccccc}
\hline $\begin{array}{c}\text { Exp. } \\
\text { No. }\end{array}$ & $\mathrm{R} 1$ & $\mathrm{R} 2$ & $\mathrm{R} 3$ & $\mathrm{R} 4$ & $\mathrm{R} 5$ & $\mathrm{R} 6$ \\
\hline 1 & 0.640 & 0.591 & 0.699 & 0.608 & 1.000 & 0.699 \\
\hline 2 & 0.701 & 0.824 & 0.351 & 0.855 & 0.735 & 0.386 \\
\hline 3 & 0.728 & 0.182 & 0.555 & 0.159 & 0.151 & 0.753 \\
\hline 4 & 0.557 & 0.583 & 0.381 & 0.872 & 0.637 & 0.888 \\
\hline 5 & 0.245 & 0.649 & 0.000 & 0.557 & 0.624 & 0.876 \\
\hline 6 & 0.657 & 0.452 & 0.682 & 0.694 & 0.911 & 0.932 \\
\hline 7 & 0.333 & 0.291 & 0.707 & 0.315 & 0.465 & 0.926 \\
\hline 8 & 0.293 & 0.437 & 0.593 & 0.597 & 0.725 & 0.660 \\
\hline 9 & 0.298 & 0.036 & 0.830 & 0.765 & 0.719 & 0.001 \\
\hline 10 & 0.421 & 0.335 & 0.754 & 0.821 & 0.869 & 0.723 \\
\hline 11 & 0.605 & 0.729 & 0.792 & 0.845 & 0.732 & 0.444 \\
\hline 12 & 0.289 & 0.299 & 0.872 & 0.000 & 0.400 & 0.776 \\
\hline 13 & 0.464 & 0.218 & 0.415 & 0.712 & 0.804 & 0.960 \\
\hline 14 & 0.061 & 0.240 & 0.779 & 1.000 & 0.676 & 0.904 \\
\hline 15 & 0.118 & 0.197 & 0.563 & 0.679 & 0.849 & 0.957 \\
\hline 16 & 0.394 & 0.116 & 0.635 & 0.262 & 0.000 & 0.945 \\
\hline 17 & 0.416 & 0.686 & 0.648 & 0.613 & 0.787 & 0.657 \\
\hline 18 & 0.175 & 0.357 & 0.766 & 0.775 & 0.260 & 0.022 \\
\hline 19 & 0.000 & 0.000 & 0.394 & 0.794 & 0.378 & 0.711 \\
\hline 20 & 0.451 & 0.255 & 0.822 & 0.849 & 0.598 & 0.294 \\
\hline 21 & 0.219 & 0.408 & 0.614 & 0.479 & 0.337 & 0.757 \\
\hline 22 & 0.482 & 0.270 & 0.190 & 0.659 & 0.556 & 1.000 \\
\hline 23 & 0.811 & 0.087 & 1.000 & 0.520 & 0.675 & 0.874 \\
\hline 24 & 0.956 & 0.919 & 0.906 & 0.268 & 0.203 & 0.916 \\
\hline 25 & 1.000 & 1.000 & 0.885 & 0.012 & 0.155 & 0.892 \\
\hline 26 & 0.837 & 0.875 & 0.508 & 0.581 & 0.477 & 0.659 \\
\hline 27 & 0.758 & 0.664 & 0.881 & 0.179 & 0.223 & 0.000 \\
\hline & & & & & & \\
\hline 12 &
\end{tabular}

\subsection{Grey relational coefficient and grey relational grade}

In grey relational analysis, the measure of the relevancy between two systems or two sequences is defined as the grey relational grade. When only one sequence, $x^{0}(k)$, is available as the reference sequence, and all other sequences serve as comparison sequences, it is called a local grey relation measurement. After data pre-processing is carried out, the grey relation coefficient $\xi_{i}(k)$ for the $k^{\text {th }}$ performance characteristics in the $i^{\text {th }}$ experiment can be expressed as:

$$
\xi_{i}(k)=\frac{\Delta_{\min }+\xi \Delta_{\max }}{\Delta_{0 i}(k)+\xi \Delta_{\max }},
$$

where: $\Delta_{o i}$ is the deviation sequence of the reference sequence and the comparability sequence.

The distinguishing coefficient $\xi$ can be substituted into Eq. 5 to deduce the grey relational coefficient. If all the process parameters are of equal weightage, then $\xi$ is 0.5 . The grey relational coefficients and grade value for each experiment is calculated by applying Eq. 5. According to the performed experiment design, it is clearly observed from Table 5; the drilling parameter setting of experiment no. 25 has the highest grey relational grade. Therefore, higher the grey relational grade indicates the optimal setting of drilling parameters in the experimentation which is identified from the experiment no. 25 shows the optimal machining parameters setting for responses measured during drilling.

Tab. 6. Grey relational coefficients and grades

\begin{tabular}{|c|c|c|c|c|c|c|}
\hline \multicolumn{6}{|c|}{ Grey relational coefficients } & \multirow{2}{*}{$\begin{array}{c}\text { Grey } \\
\text { relational } \\
\text { grades }\end{array}$} \\
\hline R1 & $\mathrm{R} 2$ & R3 & $\mathrm{R} 4$ & R5 & R6 & \\
\hline 0.581 & 0.550 & 0.624 & 0.560 & 1.000 & 0.624 & 0.6568 \\
\hline 0.626 & 0.740 & 0.435 & 0.776 & 0.653 & 0.448 & 0.6135 \\
\hline 0.647 & 0.379 & 0.529 & 0.373 & 0.370 & 0.669 & 0.4949 \\
\hline 0.530 & 0.545 & 0.446 & 0.797 & 0.579 & 0.818 & 0.6195 \\
\hline 0.398 & 0.587 & 0.333 & 0.530 & 0.571 & 0.802 & 0.5372 \\
\hline 0.593 & 0.477 & 0.611 & 0.620 & 0.850 & 0.880 & 0.6722 \\
\hline 0.428 & 0.413 & 0.630 & 0.422 & 0.483 & 0.872 & 0.5418 \\
\hline 0.414 & 0.470 & 0.551 & 0.554 & 0.645 & 0.595 & 0.5385 \\
\hline 0.416 & 0.341 & 0.746 & 0.680 & 0.640 & 0.333 & 0.5264 \\
\hline 0.463 & 0.429 & 0.670 & 0.736 & 0.793 & 0.643 & 0.6227 \\
\hline 0.558 & 0.649 & 0.706 & 0.763 & 0.651 & 0.473 & 0.6337 \\
\hline 0.413 & 0.416 & 0.797 & 0.333 & 0.454 & 0.691 & 0.5175 \\
\hline 0.483 & 0.390 & 0.460 & 0.635 & 0.719 & 0.927 & 0.6026 \\
\hline 0.347 & 0.397 & 0.694 & 1.000 & 0.607 & 0.839 & 0.6475 \\
\hline 0.361 & 0.383 & 0.533 & 0.609 & 0.768 & 0.921 & 0.5962 \\
\hline 0.452 & 0.361 & 0.578 & 0.404 & 0.333 & 0.900 & 0.5050 \\
\hline 0.461 & 0.614 & 0.587 & 0.564 & 0.701 & 0.593 & 0.5869 \\
\hline 0.377 & 0.437 & 0.682 & 0.690 & 0.403 & 0.338 & 0.4882 \\
\hline 0.333 & 0.333 & 0.452 & 0.709 & 0.445 & 0.634 & 0.4846 \\
\hline 0.476 & 0.401 & 0.737 & 0.768 & 0.554 & 0.414 & 0.5589 \\
\hline 0.390 & 0.458 & 0.564 & 0.489 & 0.430 & 0.673 & 0.5010 \\
\hline 0.491 & 0.406 & 0.381 & 0.594 & 0.529 & 1.000 & 0.5674 \\
\hline 0.726 & 0.353 & 1.000 & 0.510 & 0.606 & 0.799 & 0.6661 \\
\hline 0.919 & 0.861 & 0.842 & 0.406 & 0.385 & 0.856 & 0.7119 \\
\hline 1.000 & 1.000 & 0.813 & 0.536 & 0.672 & 0.822 & $\mathbf{0 . 8 0 7 7}$ \\
\hline 0.754 & 0.801 & 0.504 & 0.544 & 0.488 & 0.595 & 0.6147 \\
\hline 0.674 & 0.592 & 0.881 & 0.378 & 0.397 & 0.333 & 0.5307 \\
\hline
\end{tabular}

In addition to the determination of optimum drilling parameters for burr height, burr thickness, roundness error, thrust force, torque and surface roughness, the response table (multiple performance characteristics table) for the Taguchi method is used to calculate the average greyrelational grade for each level of the drilling parameters. The procedure is:

1. Group the grey relational grades by factor level for each column in an orthogonal array.

2. Take the average of grey relational grades.

From Table 7, it is observed that A3B2C2D1E2 is the order of importance of the controllable factors to the multi performance characteristics in the drilling of aluminium 7075 alloy and feed rate has the strongest effect, point and clearance angles shows the values of 
average grey relational grade, which indicates identical influence on the drilling process.

Tab. 7. Response table for average grey relational grades

\begin{tabular}{cccc}
\hline \multirow{2}{*}{$\begin{array}{c}\text { Drilling } \\
\text { parameters }\end{array}$} & \multicolumn{2}{c}{ Average grey relational grade by factor level } \\
\cline { 2 - 4 } & Level 1 & Level 2 & Level 3 \\
\hline A & 0.5779 & 0.5778 & $\mathbf{0 . 5 9 5 5}$ \\
\hline B & 0.5648 & $\mathbf{0 . 6 2 4 5}$ & 0.5618 \\
\hline C & 0.5878 & $\mathbf{0 . 6 0 8 1}$ & 0.5553 \\
\hline D & $\mathbf{0 . 6 0 9 0}$ & 0.5504 & 0.5918 \\
\hline E & 0.5916 & $\mathbf{0 . 5 9 9 7}$ & 0.5599 \\
\hline
\end{tabular}

Once the optimum combination of machining characteristics corresponding to the highest grey relational grade attained, then found the variation of each response with inputs using ANOVA, which is discussed in the subsequent section.

\section{ANALYSIS OF VARIANCE (ANOVA)}

To identify the significant effects of the input parameters over the output responses, one of the statistical techniques, utilized by most of the authors is ANOVA (analysis of variance). Most significant parameters are to be identified through ANOVA from the obtained values from Table 6; the following sequence of steps is followed.

1. The analysis of variance (ANOVA) allows an examination of the main effects of independent variables and their interactive effects to determine their combined effects on the response at $95 \%$ Confidence Interval (CI). The following statistical terms are applied to interpret the results:

2. The probability (ranging from zero to one) that the results observed in a study (or results more extreme) could have occurred by chance:

- if $P$-value $>0.10$, the parameter is insignificant,

- if $0.05<P$-value $>0.10$, the parameter is mildly significant,

- if $P$-value $<0.05$, the parameter is significant.

3. The coefficient of determination $\left(R^{2}\right)$ provides a measure of variability of the observed response values and can be explained by the controllable factors and their interactions. If the $R^{2}$ is greater than $75 \%$, the predicted model is believed to be sensitive to variation of process variables.

4. $R^{2} a d j$ is more suitable for comparing models with different numbers of independent variables. $R^{2}$ adj increases only if the new term improves the model more than would be expected. The $R^{2}$ adj will always be less than or equal to $R^{2}$.

5. The analysis of mean (ANOM) is used to determine the optimal process parametric settings by estimating the main effect of each parameter, which is presented in the main effect plot.
ANOVA test is conducted for individual responses after experimentation, by feeding inputs and grey relational grades of measured responses into the Minitab@17 software; obtain the data as depicted in Table 8 to Table 11 .

Tab. 8. Results of ANOVA for burr height

\begin{tabular}{lccccl}
\hline Input parameter & DoF & SS & MS & F & \\
\hline Spindle speed & 2 & 0.0575 & 0.0379 & 10.0 & significant \\
\hline Feed rate & 2 & 0.0348 & 0.0174 & 4.63 & significant \\
\hline Drill diameter & 2 & 0.0291 & 0.0145 & 3.87 & significant \\
\hline Point angle & 2 & 0.0426 & 0.0140 & 3.73 & significant \\
\hline Clearance angle & 2 & 0.0682 & 0.0341 & 9.07 & significant \\
\hline Error & 16 & 0.0075 & 0.0037 & & \\
\hline Total & 26 & 0.2399 & & & \\
\hline
\end{tabular}

From Table 8 for burr height, observations reveal that all input parameters are the significant for affecting the burr height, out of which speed and clearance angles are the most significant parameters. From Table 8 for burr thickness, it is understood that except clearance angle, remaining other parameters are significant with output response, spindle speed is the most significant parameter comparing to other parameters. From Table 9 for roundness error, observations reveal that except drill diameter, all the remaining parameters shows significant effect on the output response, clearance angle and spindle speed shows most significant compared to other parameters.

From Table 11 for thrust force, observed that spindle speed, feed rate, drill diameter and clearance angle are the significant parameters out of which clearance angle shows most significant than other parameters.

Tab. 9. Results of ANOVA for burr thickness

\begin{tabular}{lccccc}
\hline Input parameter & DoF & SS & MS & F & \\
\hline Spindle speed & 2 & 0.0073 & 0.0036 & 14.6 & significant \\
\hline Feed rate & 2 & 0.0048 & 0.0020 & 8 & significant \\
\hline Drill diameter & 2 & 0.0041 & 0.0020 & 8.2 & significant \\
\hline Point angle & 2 & 0.0026 & 0.0013 & 5.2 & significant \\
\hline Clearance angle & 2 & 0.0007 & 0.0003 & 1.4 & insignificant \\
\hline Error & 16 & 0.0005 & 0.0002 & & \\
\hline Total & 26 & 0.0246 & & & \\
\hline
\end{tabular}

Tab. 10. Results of ANOVA for roundness error

\begin{tabular}{lccccc}
\hline Input parameter & DoF & SS & MS & F & \\
\hline Spindle speed & 2 & 0.0747 & 0.037 & 16.2 & significant \\
\hline Feed rate & 2 & 0.0293 & 0.014 & 6.34 & significant \\
\hline Drill diameter & 2 & 0.0004 & 0.000 & 0.087 & insignificant \\
\hline Point angle & 2 & 0.0261 & 0.013 & 5.69 & significant \\
\hline Clearance angle & 2 & 0.0802 & 0.040 & 17.43 & significant \\
\hline Error & 16 & 0.0046 & 0.002 & & \\
\hline Total & 26 & 0.0152 & & & \\
\hline
\end{tabular}


Tab. 11. Results of ANOVA for thrust force

\begin{tabular}{lccccc}
\hline Input parameter & DoF & SS & MS & F & \\
\hline Spindle speed & 2 & 12568 & 6284.25 & 3.77 & significant \\
\hline Feed rate & 2 & 14961 & 7480.55 & 3.79 & significant \\
\hline Drill diameter & 2 & 17433 & 8716.75 & 4.42 & significant \\
\hline Point angle & 2 & 12318 & 6159.3 & 3.12 & insignificant \\
\hline Clearance angle & 2 & 10641 & 53206 & 5.4 & significant \\
\hline Error & 16 & 3942 & 1971 & & \\
\hline Total & 26 & 72179 & & & \\
\hline
\end{tabular}

From Table 11 for torque, observations divulges that spindle speed, diameter and clearance angle are significant effect with response, from that speed shows most significant than others. From Table 12 for surface roughness, observations reveal that spindle speed, feed rate and point angle are the significant ones, whereas point angle and speed are the most significant parameters.

Tab. 12. Results of ANOVA for torque

\begin{tabular}{lccccc}
\hline Input parameter & DoF & SS & MS & F & \\
\hline Spindle speed & 2 & 8127 & 4063.7 & 4.8 & significant \\
\hline Feed rate & 2 & 5157 & 2578.5 & 3.04 & insignificant \\
\hline Drill diameter & 2 & 6483 & 3241.6 & 3.83 & significant \\
\hline Point angle & 2 & 4161 & 2080.6 & 2.45 & insignificant \\
\hline Clearance angle & 2 & 6279 & 3139.8 & 3.71 & significant \\
\hline Error & 16 & 1694 & 846.9 & & \\
\hline Total & 26 & 31902 & & & \\
\hline
\end{tabular}

Tab. 13. Results of ANOVA for surface roughness

\begin{tabular}{lccccc}
\hline Input parameter & DoF & SS & MS & F & \\
\hline Spindle speed & 2 & 3.315 & 1.657 & 4.65 & significant \\
\hline Feed rate & 2 & 2.858 & 1.429 & 4.00 & significant \\
\hline Drill diameter & 2 & 2.372 & 1.186 & 3.32 & insignificant \\
\hline Point angle & 2 & 3.329 & 1.665 & 4.67 & significant \\
\hline Clearance angle & 2 & 1.788 & 0.894 & 2.5 & insignificant \\
\hline Error & 16 & 0.713 & 0.356 & & \\
\hline Total & 26 & 23.36 & & & \\
\hline
\end{tabular}

\subsection{Interaction plots for output responses}

Interaction effects plots represent the combined effects of factors on the dependent measure. When an interaction effect is present, the impact of one factor depends on the level of the other factor. The part of the function of ANOVA is the ability to estimate and test the interaction effects. Multiple effects should be studied in research rather than the isolated effect of single variables is one of the important contributions of Sir Ronald Fisher. The interaction between the input parameters over the output responses during the experimentation are drawn from the data means of output responses using Minitab@17.

Interaction of burr height on the input parameters for aluminium 7075 alloy plotted along the ordinate and level of parameters are selected on abscissa as shown in the Fig. 6 reveal that the burr height lowers with lower level of combined interaction of all inputs. Interaction of burr thickness over the input parameters for aluminium 7075 alloy plotted along the ordinate and level of parameters are selected on abscissa as shown in the Fig. 7 indicates, burr thickness decreases with range of moderate level combined interaction of all inputs except that the clearance angle, which is not interacted with other process parameters. The interaction of roundness error on the input parameters for aluminium 7075 alloy is chosen along the ordinate and level of parameters are selected on abscissa and plotted as shown in the Fig. 8 and then it is observed that the combined interaction of all inputs at higher level causes decrease of the output response i.e. roundness error. The interaction of thrust force on the input parameters for aluminium 7075 alloy is chosen along the ordinate and level of parameters are selected on abscissa and plotted as shown in the Fig. 9, then it is observed that the combined interaction of speed, feed, diameter and point angle at medium level causes decrease of the output response i.e thrust force.

The interaction of input parameters on torque is chosen along the abscissa and torque is selected along ordinate and plotted as shown in the Fig. 10, then it is observed that the combined interaction of spindle speed, feed and point angle at second level causes decrease of the response as a torque during drilling of aluminium 7075 alloy. The interaction of input parameters on surface roughness is chosen along the abscissa and surface roughness is selected along ordinate and plotted as shown in the Fig. 11 reveal that there is no combined interaction of input parameters on surface roughness as response during drilling of aluminium 7075 alloy.

The relative importance and statistical significance of the interaction effects between process parameters to influence the output responses are identified from ANOVA in the order of decreasing contribution of each process parameter. Then, using the most significant and interpreted input parameters again conducting an experiment to met statistical confirmation, which is discussed in the subsequent section.

\subsection{Confirmitive test}

Once the optimal level of machining parameters is assessed the final step is to predict and verify the improvement of the performance characteristics using the optimal level of the machining parameters. The estimated response value using the optimum level of the machining parameter $(\hat{\gamma})$ can be calculated as:

$$
\hat{\gamma}=\gamma_{m}+\sum_{i=1}^{\lambda}\left((\bar{\gamma})_{j}-\gamma_{m}\right),
$$

where $\gamma_{m}$ is the total mean of the response value, $\overline{\gamma_{j}}$ is the mean of the response value at the optimum level, $i=1,2 \ldots 6$ and ' $\lambda$ ' is the number of machining parameters that significantly effects the multiple performance characteristics. The optimal combination of drilling input parameters to be determined and presented under results and discussions. 


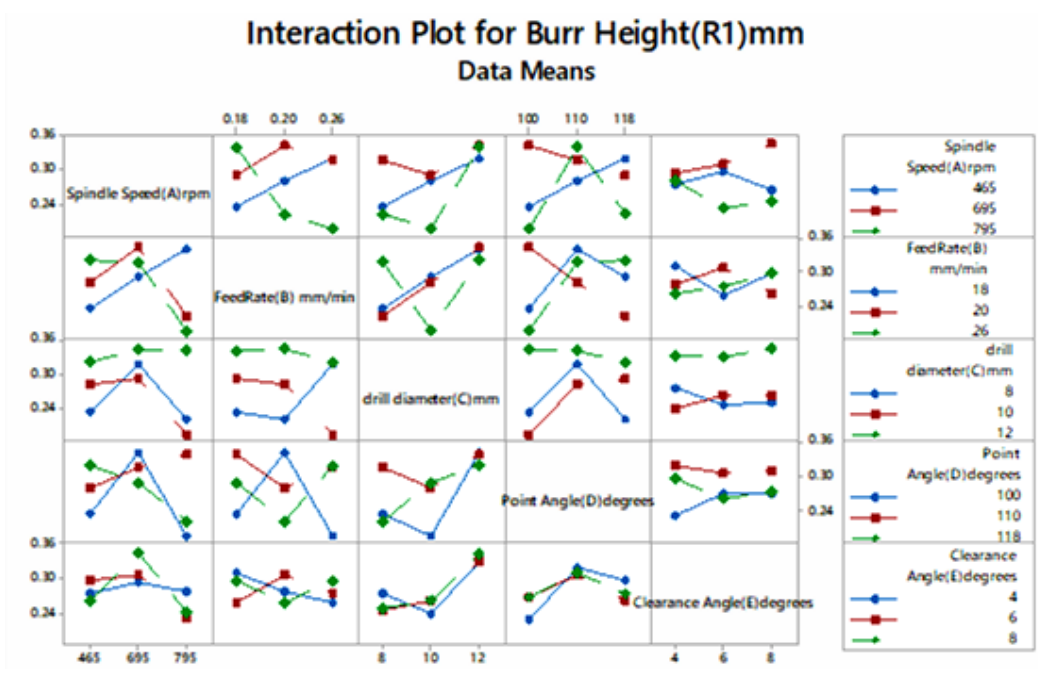

Fig. 6. Interaction plot for burr height

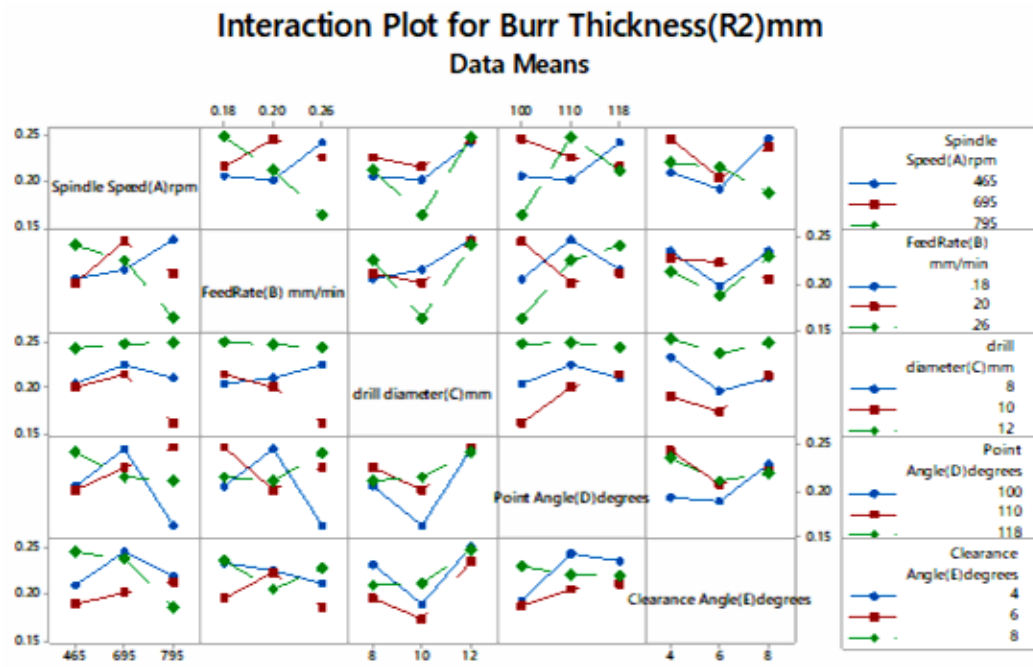

Fig. 7. Interaction plot for burr thickness

\section{Interaction Plot for Roundness Error(R3)mm Data Means}

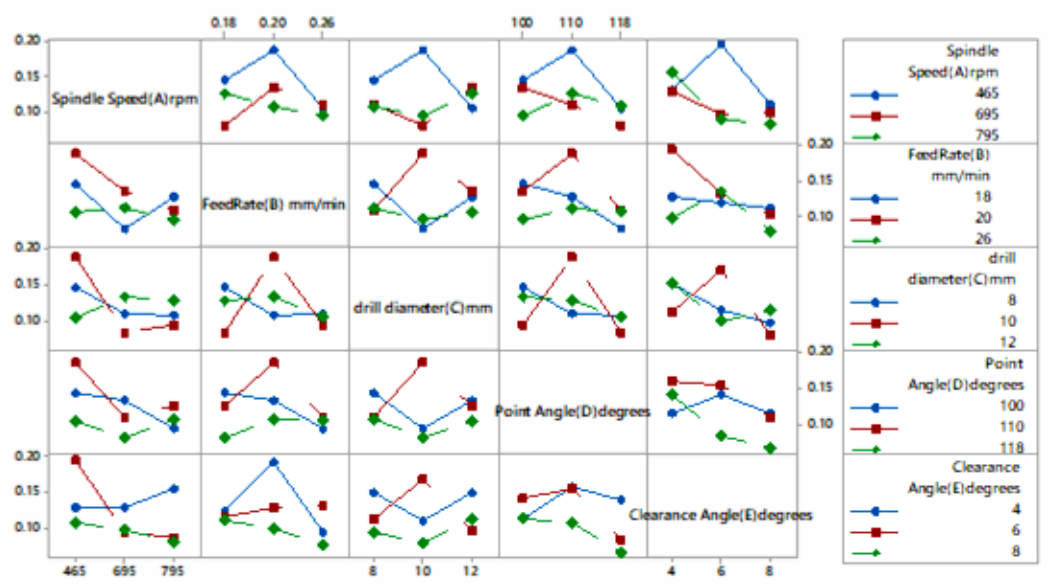

Fig. 8. Interaction plot for roundness error 


\section{Interaction Plot for Thrust Force(R4)N}

\section{Data Means}

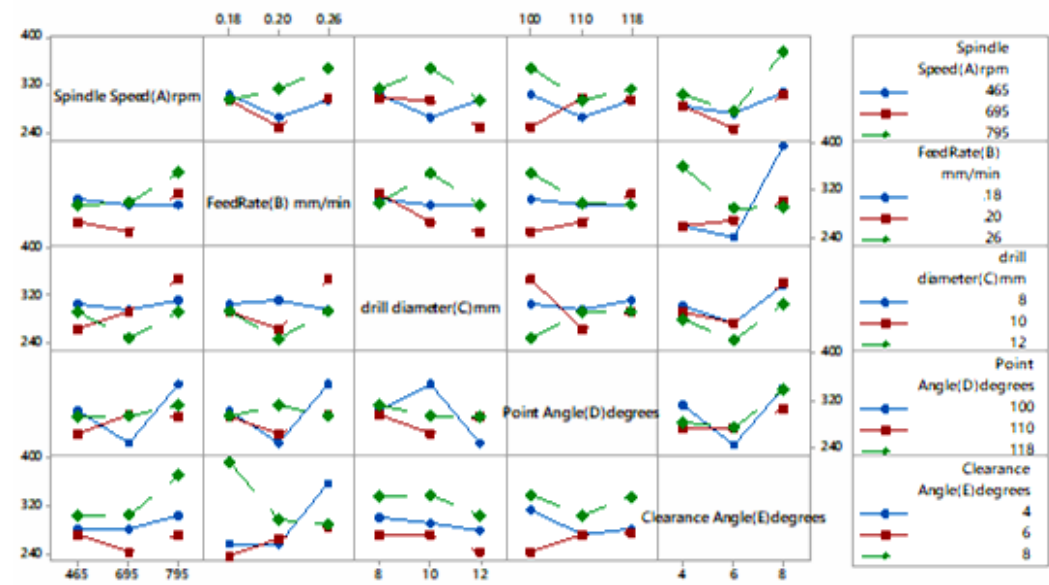

Fig. 9. Interaction plot for thrust force

\section{Interaction Plot for Torque(R5)Nm Data Means}

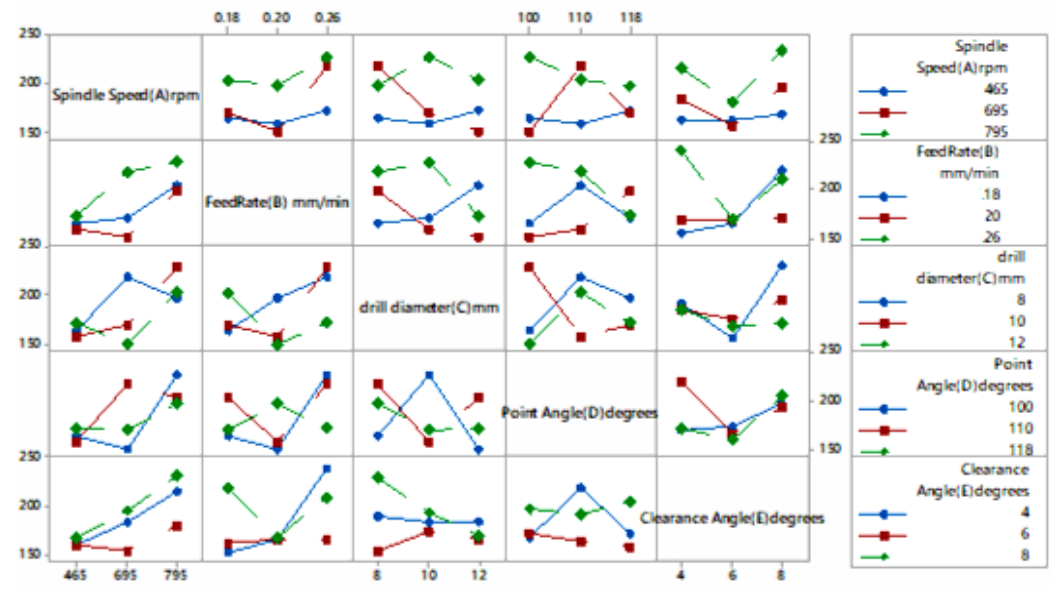

Fig. 10. Interaction plot for torque

\section{Interaction Plot for Surface Roughness(R6) $\mu \mathrm{m}$} Data Means

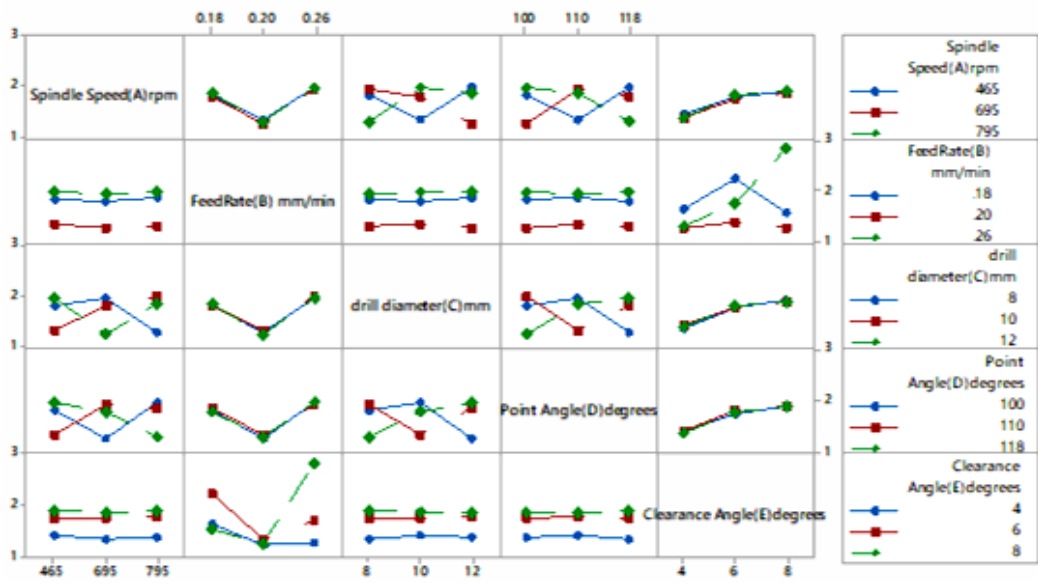

Fig. 11. Interaction plot for surface roughness 


\section{RESULTS AND DISCUSSIONS}

\subsection{Results obtained from Grey based Taguchi approach}

To know the weightage of influencing input parameters over the output responses in level wise, the graphs are drawn between the levels of input parameters versus average grey relational grades. The observations made from Fig. 12 shows that higher the range of spindle speed influence more on responses; feed rate, clearance angle and drill diameter are showing moderate influence over the output responses. Finally, found that the lower range of point angles influences more on the output responses during drilling of Al 7075 alloy.

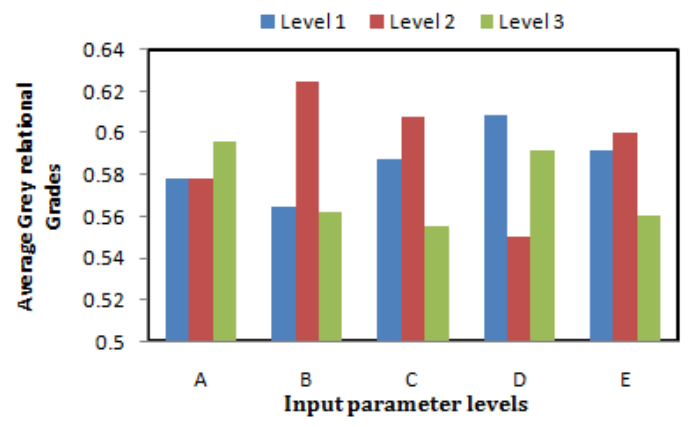

Fig. 12. The weightage of influencing input parameters over the output responses in level wise with reference to average grey relational grades

\subsection{Results obtained from ANOVA}

The results obtained from the experimentation are tested for confirmation of significant parameters and their interaction between the other parameters through ANOVA, as discussed in earlier sections. The relative importance and statistical significance of the main and interaction effects between process input parameters to influence the output responses are identified from ANOVA in the order of decreasing contribution of each parameter. To test whether the developed hypothesis is correct or not can be known from the obtained statistical data such as $R^{2}, R^{2}$ (pred) and $R^{2}$ (adj) values obtained from Minitab@17 software in the analysis of variance in data means of output responses.

Table 14 indicates that the coefficient of determination $\left(R^{2}\right)$ of the observed responses viz., burr height, burr thickness, roundness error, thrust force, torque and surface roughness of the proposed approach believed to be sensitive for the variation of input process parameters during drilling of aluminium alloys. Based on Eq. 6, the estimated burr height, burr thickness, roundness error, thrust force, torque and surface roughness values for the optimal machining parameters can be obtained. Table 15 shows the results of the confirmation experiment setting for the optimal machining parameters.
Tab. 14. Percentage of coefficients of determination $\left(R^{2}\right)$ of observed responses

\begin{tabular}{lccc}
\hline Output Response & $R^{2}, \%$ & $R^{2} a d j, \%$ & $R^{2}$ pred, $\%$ \\
\hline Burr height & 92.87 & 90.43 & 89.72 \\
\hline Burr thickness & 93.24 & 90.59 & 90.00 \\
\hline Roundness error & 94.66 & 92.51 & 89.78 \\
\hline Thrust force & 98.54 & 91.74 & 90.33 \\
\hline Torque & 79.59 & 78.68 & 80.25 \\
\hline Surface roughness & 98.26 & 95.48 & 91.86 \\
\hline
\end{tabular}

Tab. 15. Optimal values of individual machining characteristics

\begin{tabular}{lcccc}
\hline Output & $\begin{array}{c}\text { Optimal } \\
\text { combination of } \\
\text { parameters }\end{array}$ & $\begin{array}{c}\text { Significant } \\
\text { parameters }\end{array}$ & $\begin{array}{c}\text { Predicted } \\
\text { optimum } \\
\text { value }\end{array}$ & $\begin{array}{c}\text { Experime } \\
\text { ntal value }\end{array}$ \\
\hline $\mathrm{R}_{1}$ & $\mathrm{~A}_{2} \mathrm{~B}_{1} \mathrm{C}_{3} \mathrm{D}_{2} \mathrm{E}_{3}$ & A,B,C,D,E & 0.156 & 0.164 \\
\hline $\mathrm{R}_{2}$ & $\mathrm{~A}_{2} \mathrm{~B}_{1} \mathrm{C}_{3} \mathrm{D}_{2} \mathrm{E}_{1}$ & $\mathrm{~A}, \mathrm{~B}, \mathrm{C}, \mathrm{D}$ & 0.138 & 0.141 \\
\hline $\mathrm{R}_{3}$ & $\mathrm{~A}_{1} \mathrm{~B}_{2} \mathrm{C}_{3} \mathrm{D}_{2} \mathrm{E}_{1}$ & $\mathrm{~A}, \mathrm{~B}, \mathrm{D}, \mathrm{E}$ & 0.053 & 0.063 \\
\hline $\mathrm{R}_{4}$ & $\mathrm{~A}_{3} \mathrm{~B}_{3} \mathrm{C}_{1} \mathrm{D}_{1} \mathrm{E}_{3}$ & $\mathrm{~A}, \mathrm{~B}, \mathrm{C}, \mathrm{E}$ & 379.8 & 396.9 \\
\hline $\mathrm{R}_{5}$ & $\mathrm{~A}_{3} \mathrm{~B}_{3} \mathrm{C}_{1} \mathrm{D}_{2} \mathrm{E}_{3}$ & A,C,E & 235.6 & 249.1 \\
\hline $\mathrm{R}_{6}$ & $\mathrm{~A}_{3} \mathrm{~B}_{3} \mathrm{C}_{2} \mathrm{D}_{2} \mathrm{E}_{3}$ & A,B,D & 1.306 & 1.326 \\
\hline
\end{tabular}

\section{CONCLUSIONS}

The conclusions obtained from the present work performed to evaluate burr size (height and thickness), roundness error, thrust force, torque and surface roughness during experimentation. The output responses obtained from experimentation using Grey based Taguchi approach is as follows.

1. The experimental results reveal that the feed rate, point angle and clearance angles are the most influencing parameters on burr height, thrust force, roundness error and surface roughness than the spindle speed and drill diameter.

2. Statistical model deduced from the interaction plots obtained from ANOVA divulges that the combined influence of each input parameter over the other parameters on multiple output responses, confirms that in drilling of Al 7075 alloys for all cutting conditions tested and the burr height, burr thickness, roundness error, thrust force, surface roughness and torque are close to those obtained in drilling experimentation as, the output responses viz., burr height, burr thickness, roundness error, thrust force, surface roughness and torque are improved by $4.87 \%, 2.12 \%, 7.93 \%, 4.32 \%, 5.41 \%$ and $3.16 \%$ respectively.

\section{Nomenclature}

$$
\begin{array}{ll}
\text { Symbols } \\
R_{1} \quad-\text { burr height, } \mathrm{mm} \\
R_{2} \quad-\text { burr thickness, } \mathrm{mm} \\
R_{3} \quad-\text { roundness error, } \mathrm{mm} \\
R_{4} \quad-\text { thrust force, } \mathrm{N} \\
R_{5} \quad-\text { torque, } \mathrm{Nm} \\
R_{6} \quad-\text { surface roughness, } \mu \mathrm{m}
\end{array}
$$




\section{Greek letters}

$\xi \quad-$ Grey Relational Coefficient

$\hat{\gamma} \quad-$ Optimum Level of Machining Parameter

$\gamma_{m} \quad-$ Total Mean of Response

\section{References}

1. Gillespie, L. K. and Blotter, FT (1976). The Formation and Properties of Machining Burrs, Transactions of ASME, Journal of Engineering for Industry, Volume 98, No. 2 (1976), pp. 66-74.

2. Kim J, Min S, Dornfeld D (2001), Optimization and Control of Drilling Burr Formation of AISI 304L and AISI 4118 Based on Drilling Burr Control Charts. International Journal of Machine Tools \& Manufacture, Vol 41(7), pp. 923-936.

3. Reddy Sreenivasulu, Ch.Srinivasa Rao (2013), Design of Experiments based Grey Relational Analysis in Various Machining Processes - A Review, Research Journal of Engineering Sciences (International Science Congress Association) Vol. 2 (1), pp 21-26.

4. Reddy Sreenivasulu, Ch.Srinivasa Rao (2018), Modelling, Simulation and Experimental validation of Burr size in Drilling of Aluminium 6061 alloy, Procedia Manufacturing (Elsevier), Vol 20, pp 458-463.

5. Reddy Sreenivasulu, Ch. Srinivasa Rao and K. Ravindra (2019), Grey based Taguchi approach integrated with Entropy Measurement for optimization of Surface Roughness and Delamination Damage factor during End Milling of GFRP Composites, International Journal of Modern Manufacturing Technologies, Vol XI, Issue 2, pp 133-141.

6. D.F. Galloway (1957), Some experiments on the influence of various factors on drill performance, Transactions of the ASME, Vol 79, pp. 191-231.

7. Gillespie, L. K (1998). An integrated international standard for burrs and edge finishing, report WBTC STD-14, Deburring Technology International, Inc., Kansas City, MO.

8. J.Hirsch (2014), Recent development in aluminium for automotive applications, Transactions of Nonferrous Metals Society of China, Vol 24, pp. 1995-2002.

9. Gillespie, L. K (1975). Burrs Produced by Drilling, Bendix Corporation, Unclassified Topical Report, pp.613-1248.

10. Gillespie, L. K (1976). Effects of Drilling Variables on Burr Properties, Bendix Corporation, Unclassified Topical Report, pp.613- 1502.

11. Sofronas, A., Spurgeon, M and Taraman, K., Reduction of Burr Formation in Drilling, SME Technical Papers (1975), MR 75-376, Detroit, Ml.

12. Deng Julong (1989), Introduction to Grey system theory, Journal of Grey system, , Vol 1, pp. 1-24.

13. Sreenivasulu R., Rao Ch. S.(2020) Optimization of machining parameters during end milling of super alloys using grey based Taguchi method coupled with entropy measurement technique. Journal of Mechanical and Energy Engineering, Vol. 4(44), No. 1, pp. 47-56.

14. Sreenivasulu, R., \& SrinivasaRao, C. (2019). Review on Investigations Carried out on Burr Formation in Drilling During 1975 To 2020. Technological Engineering, Vol 16(1), 43-57.

15. Md Zakir Hussain, Sabah Khan, Pranjal Sarmah (2020) Optimization of powder metallurgy processing parameters of $\mathrm{Al} 2 \mathrm{O} 3 / \mathrm{Cu}$ composite through Taguchi method with Grey relational analysis, Journal of King Saud University - Engineering Sciences, Vol 32, pp 274-286.

16. Sreenivasulu, R., SrinivasaRao, C. (2019). Review on Investigations Carried out on Burr Formation in Drilling During 1975 To 2020, Technological Engineering, Vol 16 No.1, pp 43-57.

\section{Biographical notes}

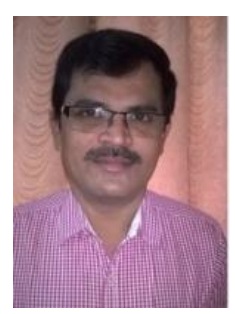

Reddy Sreenivasulu is Assistant Professor in the department of Mechanical Engineering, R.V.R \& J.C College of Engineering (A) Guntur, Andhra Pradesh, India. $\mathrm{He}$ received $\mathrm{Ph} . \mathrm{D}$ degree from Andhra University, Visakhapatnam in the year 2018, M.E degree from the Osmania University, Hyderabad in the year 2003 and B.Tech Mechanical Engineering from Regional Engineering College Warangal in the year 1997. He has 19 years of teaching experience. His area of research interest includes design of experiments, robotics, modeling and analysis of manufacturing processes and optimization. He has published more than 60 research papers in the international journal/conferences proceedings and acting as a reviewer for a peer reviewed referred journals.

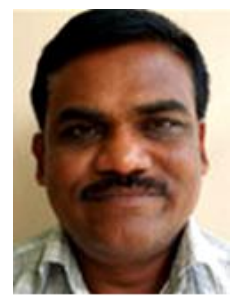

Ch. Srinivasa Rao is a professor in Mechanical Engineering Department of Andhra University College of Engineering, Visakhapatnam. He guided more than 10 research scholars and several Post Graduate students in various domains of Mechanical Engineering. He published more than 150 national and international journals with high eminence. 